\title{
Genetic Diversity of the Mating Type and Toxin Production Genes in Pyrenophora tritici-repentis
}

\author{
P. Lepoint, M.-E. Renard, A. Legrève, E. Duveiller, and H. Maraite
}

First, second, third, and fifth authors: Unité de Phytopathologie, Université catholique de Louvain, BE-1348 Louvain-la-Neuve, Belgium; and fourth author: Global Wheat Program, CIMMYT, 06600 México D.F., México.

Accepted for publication 5 January 2010.

\section{ABSTRACT}

Lepoint, P., Renard, M.-E., Legrève, A., Duveiller, E., and Maraite, H. 2010. Genetic diversity of the mating type and toxin production genes in Pyrenophora tritici-repentis. Phytopathology 100:474-483.

Pyrenophora tritici-repentis, the causal agent of tan spot on wheat, is a homothallic loculoascomycete with a complex race structure. The objectives of this study were to confirm the homothallic nature of the pathogen, characterize mating type diversity and toxin production genes in a global collection of strains, and analyze how these traits are associated between each other and with existing races. The pseudothecia production capacity, race identification, mating type locus (MAT), internal transcribed spacer, and glyceraldehyde-3-phosphate dehydrogenase regions were analyzed in a selection of 88 strains originating from Europe, North and South America, North Africa, and Central and South Asia. Some $(60 \%)$ strains produced pseudothecia containing ascospores, independent of their origin. Race identification obtained using the multiplex polymerase chain reaction targeting host-selective toxin (HST) genes was consistent, overall, with the results based on the inoculation of a set of differential wheat cultivars and confirmed the predominance of race $1 / 2$ strains $(\approx 83 \%)$. However, discrepancies in race identification, differences from the reference tester strains, and atypical ToxA profiles suggest the presence of new races and HSTs. The MAT1-1 and MAT1-2 coding regions are consecutively arranged in a single individual, suggesting putative heterothallic origin of $P$. tritici-repentis. Upstream from the $M A T$ is an open reading frame of unknown function (ORF1) containing a MATspecific degenerate carboxy-terminus. The phylogenetic analysis of the MAT locus reveals two distinct groups, unlinked to geographical origin or ToxA profile. Group I, the best-represented group, is associated with typical tan spot lesions caused by races $1,2,3$, and 5 on wheat. It is more homogenous than group II encompassing race 4 strains, as well as isolates associated primarily with small spot lesions on wheat leaves or other hosts. Group II could contain several distinct taxa.

Additional keywords: Drechslera tritici-repentis, $\mathrm{Ptr}$ ToxB, toxb.
Pyrenophora tritici-repentis (Died.) Drechsler (anamorph, Drechslera tritici-repentis (Died.) Shoemaker) is the causal agent of tan spot, a major foliar blight disease in temperate and warmer wheat-growing areas throughout the world $(17,29,33,36,37,56) . P$. tritici-repentis nomenclature has undergone changes since its initial description in 1903 by Diedicke (14), having previously been referred to as Helminthosporium gramineum f. sp. triticirepentis, $H$. tritici-vulgaris, and $H$. tritici-repentis for the anamorph, and Pleospora trichostoma and Pyrenophora trichostoma for the teleomorph (31).

$P$. tritici-repentis is isolated mainly from wheat but it has been reported on other cereals, such as rye and barley, in addition to numerous grasses (i.e., Agropyron spp.) (1,24). Symptoms observed on susceptible wheat cultivars are tan necrosis or fairly extensive chlorosis (25). The recent increase in the importance of this disease is due partly to reduced or zero-tillage practices that allow stubble retention on the soil, shorter crop rotations, or continuous wheat cultivation. These practices favor the pathogen overwintering on residues and the formation of the teleomorph, thus completing the full disease cycle $(9,19)$. The extension of wheat cultivation into nontraditional, warmer environments also plays a major role in the increase in tan spot incidence. In these regions, the crop is grown in the cool season and disease control relies primarily on host genetic resistance.

$P$. tritici-repentis has been reported as a homothallic (selffertile) loculoascomycete, implying that it does not require a

Corresponding author: H. Maraite; E-mail address: henri.maraite@uclouvain.be

doi:10.1094/PHYTO-100-5-0474

(c) 2010 The American Phytopathological Society partner to mate. In nature, a single sexual cycle is completed in the growing season after overwintering on the stubble left in the field, whereas several cycles of asexual reproduction can occur during the same period $(11,19)$. Conversely, large quantities of fertile pseudothecia can be produced in vitro on maize leaf water agar in as little as 4 weeks under specific light and temperature conditions $(13,21)$.

The techniques used to characterize $P$. tritici-repentis isolates have evolved in conjunction with a better understanding of the pathogen and its interaction with its main host, wheat (25-27). Currently, a race designation system based on putative necrosis or chlorosis symptoms induced on a wheat differential set (27) distinguishes at least eight races $(4,27,28,43,47,48)$. The number of races described is linked to the number of wheat cultivars included in the differential set, which could hamper the identification of new races. In practice, phenotypic race classification appears rather subjective and can depend on the observer, as well as being potentially restrictive as shown by Andrie et al. (4). The chlorosis symptom may evolve rapidly to necrosis, leading to confusion. Ideally, therefore, it should be accompanied by molecular confirmation of the presence of host-selective toxins (HSTs) associated with the necrosis or chlorosis symptoms observed. This can be carried out in view of the fact that the necrosis symptoms observed on certain wheat genotypes are induced by the HST Ptr ToxA (synonyms: Ptr necrosis toxin, Ptr toxin, ToxA) $(6,51,52,58)$ and that chlorosis is induced on certain wheat differential genotypes by the production of either Ptr ToxB (synonym: Ptr chlorosis toxin) (10) or Ptr ToxC (18). ToxB and ToxC can be differentiated with selected wheat genotypes (48). Also, ToxB-like sequences ( $T o x B v$, high sequence identity to ToxB) have been identified in race 3 strains $(46,47)$ and toxb sequences (lower se- 
quence identity to ToxB) in race 4 strains $(34,47)$, although neither produce Ptr ToxB. Representative strains of races 1 to 5 , as well as two field isolates, were characterized by Andrie et al. (4) using traditional phenotypic and a new genotypic multiplex polymerase chain reaction (PCR) method allowing the presence or absence of ToxA, ToxB, ToxB-like, and toxb sequences to be detected. However, there is room for improvement because the multiplex PCR is unable to distinguish race 1 from race 2 and race 3 from race 5 . Also, for some strains, phenotypic and genotypic race identification does not always correspond, suggesting the existence of at least two supplementary races and possibly an additional HST Ptr ToxD (4).

Phylogenetic analysis based on combined data sets of internal transcribed spacer (ITS) regions, nuclear gene coding region glyceraldehyde-3-phosphate dehydrogenase $(g p d)$, and mating type locus (MAT)-2 HMG box sequences of Pyrenophora spp. and other members of the family Pleosporaceae revealed $P$. bromi as $P$. tritici-repentis's closest relative $(5,8,57)$. Homologs of ToxB have been demonstrated in the genome of $P$. bromi and other members of the Ascomycota, suggesting that this gene originated at an early stage of fungal evolution and has been lost or retained by some lineages (5). In contrast, Friesen et al. (22) discovered a gene in the genome sequence of Phaeosphaeria nodorum with $99.7 \%$ similarity to ToxA, suggesting a lateral gene transfer that occurred just before 1941. This transfer appears to correspond to the sudden increase in tan spot and the reports of more severe symptoms. Infraspecific genetic diversity has been detected in Pyrenophora tritici-repentis by random amplified polymorphic DNA analysis $(15,39,43)$ and on a minor scale in ITS sequences (57). However, no correlation has yet been described linking $P$. tritici-repentis genetic diversity to geographic origin or race.

Within the context of collaborative research programs on leaf blights on wheat between Université catholique de Louvain (UCL) and Centro Internacional de Mejoramiento de Maiz y Trigo (CIMMYT) (the Spanish acronym for the International Wheat and Maize Improvement Center), an extensive collection of $P$. tritici-repentis strains from Europe, North and South America, North Africa, and Central and South Asia has been collected over two decades. This collection provides the opportunity to study $P$. tritici-repentis diversity around the world.

The objectives of this study, based on the global collection of strains mentioned above, were to (i) verify the homothallic nature of $P$. tritici-repentis from the various origins by analyzing the teleomorph production capacity in vitro, (ii) analyze the organization and the putative diversity of the MAT gene within the pathogen population, (iii) compare the phenotypic and genotypic race identification of a large set of strains for the possible identification of individuals with unexpected toxin production profiles that could be good candidates for the description of new races, and (iv) explore the link between genetic diversity, geographic origin, and pathogenicity.

\section{MATERIALS AND METHODS}

P. tritici-repentis strains. An extensive collection of $P$. triticirepentis strains has been established from naturally infected leaves collected mainly through a series of field surveys conducted with CIMMYT since the late 1980 s in wheat-growing areas worldwide. A selection of 82 monoconidial $P$. tritici-repentis strains was used for this study and deposited at the Mycothèque de l'Université catholique de Louvain (MUCL, Louvain-la-Neuve, Belgium), the agro-industrial fungi and yeast collection of the Belgian coordinated collections of microorganisms, Brussels. The collection was completed for comparison with the following $P$. tritici-repentis representative strains for races 1 to 5: Pti2 for race 1 (20), 86-124 for race $2(4,15,20,26,27), 331-9$ for race 3 $(15,20), 90-2$ for race $4(27,43)$, and DW7 for race $5(2,4)$. Strain
MUCL 18687 (= Centraalbureau voor Schimmelcultures [CBS] 259.59) (Utrecht, The Netherlands), previously identified as a syntype of $H$. tritici-vulgaris (Nisikado) (later reidentified as $P$. tritici-repentis), was also included in the study performed in 2007. Conidia production of $P$. tritici-repentis colonies on V8PDA (15\% [vol/vol] V8 juice, $0.3 \%$ [wt/vol] $\mathrm{CaCO}_{3}, 1 \%$ [wt/vol] potato dextrose agar [Oxoid, Cambridge, UK], and $1 \%$ [wt/vol] agar) was induced using the conditions described by Lamari and Bernier $(25,26)$. The confirmation that the strains belonged to $P$. tritici-repentis was based on the typical "snake-head" form of terminal conidial cells (16) and, in dubious cases, on ITS analysis. The race phenotype of 75 strains, including the reference strains, had been previously characterized at Unité de Phytopathologie $(15,33)$ by inoculation on a set of four hexaploid wheat lines or cultivars (Glenlea, 6B-365, 6B-662, and Salamouni) with known reaction type to the eight races of $P$. tritici-repentis (28). Seedlings were produced on a 1:1 compost:peat substrate in an airconditioned greenhouse (20 to 22 and 16 to $17^{\circ} \mathrm{C}$ day and night temperatures, respectively, with a $16-\mathrm{h}$ photoperiod). At the threeleaf stage, they were inoculated with 2,000 conidia/ml until runoff. Inoculated seedlings were moved for $24 \mathrm{~h}$ to a mist chamber at $21^{\circ} \mathrm{C}$ with a 16 -h photoperiod, before returning to the greenhouse or a growth room with similar conditions. They were rated for reaction type 7 days after inoculation using the scale described by Lamari and Bernier (25). Race identification was inferred from these ratings (28) (Table 1).

Teleomorph production. The strains were tested for their capacity to produce pseudothecia containing viable ascospores, using a modified version of the Friesen et al. (21) method. Autoclaved green maize leaf sections, $\approx 4 \mathrm{~cm}$ long, were placed on $2 \%$ water agar plates. Instead of inoculating the leaves with a calibrated conidial suspension, 4-mm plugs taken from an active colony margin of a young ( $\approx 5$ days old) culture grown on V8PDA were used. Each plate was inoculated with three equidistant ( $\approx 1.5 \mathrm{~cm}$ apart) plugs of the same strain along the length of the leaf, mycelium side down. Parafilm-sealed plates were incubated for 3 days at $25^{\circ} \mathrm{C}$ in the dark before being placed under cool white fluorescent tubes $(\approx 3,200$ Lux, Sylvania Standard F58W/ 133-T8; Osram-Sylvania, München, Germany) at $15 \pm 1.5^{\circ} \mathrm{C}$ and a 12-h photoperiod. Triplicates per strain were conducted on at least two consecutive occasions. If no fertile pseudothecia were produced, a third trial was carried out.

DNA extraction and amplification of ITS and gpd regions. DNA was extracted according to the supplier's recommendations using the FastDNA Kit (Qbiogene, Carlsbad, CA) and quantified with a NanoDrop ND-1000 spectrophotometer (Thermo Scientific, Wilmington, DE). The ITS regions were PCR amplified using universal primers NS7 and ITS4 (54). The region coding for the nuclear gene gpd was amplified using primer pair $g p d 1 / g p d 2$ (8). The ITS PCR amplifications were performed with $50 \mathrm{ng}$ of DNA template in a total volume of $50 \mu$ containing $2.5 \mathrm{mM}$ $\mathrm{MgCl}_{2}$ (Fermentas $\mathrm{GmbH}$, St. Leon-Rot, Germany), $300 \mu \mathrm{M}$ each dNTP, $400 \mathrm{nM}$ each primer, Taq DNA polymerase buffer, and $0.25 \mathrm{U}$ of Taq DNA polymerase (Invitrogen Life Technologies, Carlsbad, CA). The gpd PCR reaction mixtures (total volume of $50 \mu \mathrm{l}$ ) contained $20 \mathrm{ng}$ of DNA in a $1 \times$ PCR buffer, $2.5 \mathrm{mM}$ $\mathrm{MgCl}_{2}, 0.25 \mathrm{mM}$ concentration of each dNTP, $100 \mathrm{nM}$ concentrations of each primer, and $0.5 \mathrm{U}$ of Taq DNA polymerase. All PCRs were performed in an MJ Mini Gradient Thermal Cycler (PTC-1148; Bio-Rad, CA) with the following ITS cycling conditions: initial denaturation at $94^{\circ} \mathrm{C}$ for $3 \mathrm{~min}$ followed by 35 cycles of $94^{\circ} \mathrm{C}$ for $30 \mathrm{~s}, 60^{\circ} \mathrm{C}$ for $30 \mathrm{~s}$, and $72^{\circ} \mathrm{C}$ for $1 \mathrm{~min}$. A final extension was performed at $72^{\circ} \mathrm{C}$ for $7 \mathrm{~min}$. The gpd cycling conditions were $95^{\circ} \mathrm{C}$ for $3 \mathrm{~min}$; followed by 30 cycles of $94^{\circ} \mathrm{C}$ for $1 \mathrm{~min}, 60^{\circ} \mathrm{C}$ for $30 \mathrm{~s}$, and $72^{\circ} \mathrm{C}$ for $1 \mathrm{~min}$; and a final extension at $72^{\circ} \mathrm{C}$ for $10 \mathrm{~min}$. The PCR products were purified with a MSB Spin PCRapace Kit 250 (Invitek GmbH, Berlin) following the suppliers' recommendations. 
Amplification of MAT region. Nine MAT idiomorph primers spanning the entire hypothetical idiomorph were designed, based on the alignment of the $P$. tritici-repentis Pt-1C-BFP strain genome sequence obtained from the $P$. tritici-repentis sequencing project (Broad Institute of Harvard and MIT, http://www.broad.mit.edu) and available MAT1-1 (AY950585) and MAT1-2 (AY950586) sequences of $P$. teres strains. The PCR strategy used, and the primer locations and organization of coding regions within the $M A T$ region, are shown in Figure 1. Primer sequences are given in Table 2. The PCR and amplification conditions used were identical to those used for the $g p d$ gene.

Sequence diversity analysis. Sequencing reactions were performed using a CEQ DTCS Quick start Kit (Beckman Coulter Inc., Fullerton, CA), and nucleotide sequence chromatograms were obtained with a CEQ 2000 XL capillary automated sequencer (Beckman Coulter Inc.). Raw data were analyzed and edited using the sequence analysis software program Sequencher v.4.6 (Gene Code Corporation, Ann Arbor, MI), before being aligned automatically with ClustalW 1.82 and manually corrected using BioEdit Sequence Alignment Editor v.5.0.9 (North Carolina State University). Searches were done against the GenBank/ EMBL databases using BLASTN 2.2.9 (3).

The accession numbers for the $g p d$, ITS, and MAT sequences deposited in the EMBL database were AM884257 to AM884276, AM887493 to AM887511, and AM884582 to AM884620, respectively.

The phylogenetic relationships between $P$. tritici-repentis strains were inferred from the maximum parsimony analysis of MAT sequences using the PAUP* version 4.0b10 phylogenetics package (Swofford). Heuristic searches (1,000 replicates) were performed using random sequence addition by means of a treebisection-reconnection branch-swapping algorithm, with gaps considered to be a fifth character state. Confidence in the branching points was established by performing 1,000 bootstrap repli-

TABLE 1. Pyrenophora tritici-repentis strains analyzed in this investigation and synopsis of results ${ }^{\mathrm{a}}$

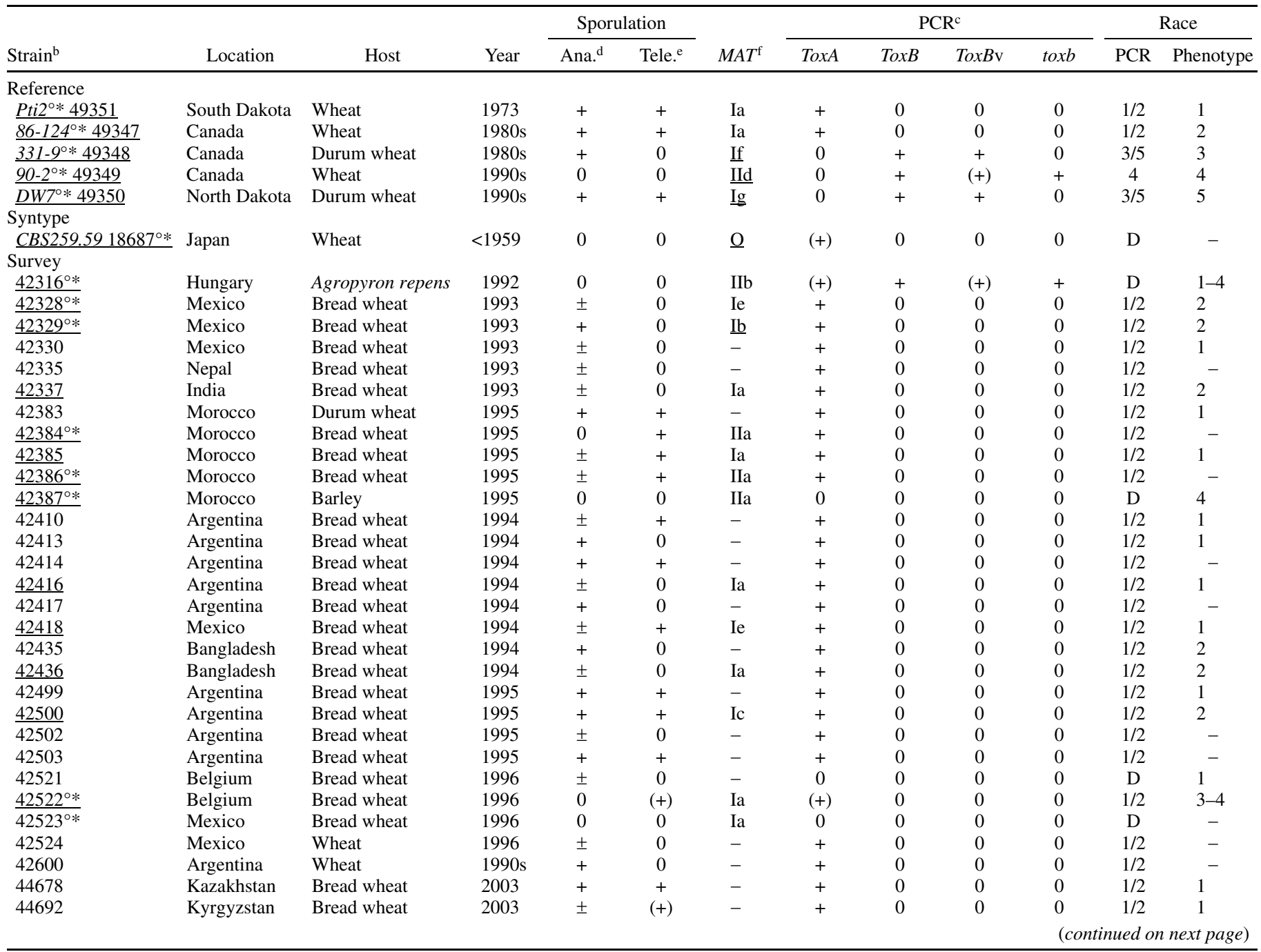

${ }^{a} \mathrm{D}$ indicates results different from reference strains and - indicates information not available.

${ }^{\mathrm{b}}$ Reference $=$ race reference strains and Survey $=$ Strains from own surveys. Reference strain number in italics, Mycothèque de 1'Université catholique de Louvain accession number in normal figures. Strains for which the glyceraldehyde-3-phosphate dehydrogenase $\left({ }^{\circ}\right)$, internal transcribed spacer $(*)$, and mating type region (underlined accession number) were sequenced in this study and submitted to the EMBL database are indicated.

${ }^{c}$ Multiplex polymerase chain reaction (PCR) (4) with primers TA51F/TA52R (ToxA in races 1 and 2), TB71F/TB6R (ToxB in races 3, 4 and 5), TB71F/TB60R $(T o x B v$ for ToxB-like in races 3 and 5), and TB71F/TB58R (toxb in race 4$) ;+=$ fragment of expected size, $(+)=$ weak amplification of fragment of expected size, $0=$ no amplicon observed, and $*=$ fragment of unexpected size.

d Anamorph production of strains was identified as: + conidia production average to very abundant, \pm below average, 0 no conidia or conidiophores observed.

e Teleomorph production on maize water agar was identified as: + pseudothecia producing ascospores, $(+)$ pseudothecial initials, 0 no structures observed.

${ }^{\mathrm{f}}$ Mating type locus (MAT) haplotypes are groups of strains with identical mating-type sequences. The roman numerals indicate the phylogenetic group and lowercase letters indicate subgroups. Underlined entries indicate a unique haplotype for that strain and $\mathrm{O}$ indicates that all expected fragments were not amplified. 
cates using maximum parsimony as the criterion and random sequence addition. Phylogenetic analysis was carried out in this way by using subsequently, as outgroups, available $P$. teres sequences and the $P$. tritici-repentis sequence MUCL 45128 (grouping with no other $P$. tritici-repentis strain). Given that $P$. teres is a heterothallic fungus, MAT1-1 (AY950585) and MAT1-2 (AY950586) sequences were combined to reflect the $M A T$ structure of $P$. tritici-repentis.

Identification of races by PCR. In order to complement the visual assessment of disease phenotype for race designation, race genotype identification was carried out on $P$. tritici-repentis strains using the multiplex PCR designed by Andrie et al. (4), targeting specific portions of the ToxA (primers TA51F/TA52R) and ToxB/ToxB-like/toxb (TB71F/TB6R, TB60R, or TB58R) open reading frames (ORFs). In theory, ToxA primers amplify an $\approx 600$-bp fragment only in race 1 and 2 strains, whereas races 3,4 , and 5 yield an $\approx 250$-bp amplicon specific to ToxB using primer pair TB71F/TB6R. Reverse primer TB60R paired with TB71F is specific to ToxB-like sequences that are characteristic of races 3 and 5, whereas reverse primer TB58R is specific to toxb in race 4.

\section{RESULTS}

Morphological diversity and teleomorph development. All the sporulating strains presented the characteristic $P$. triticirepentis conidial morphology despite the variations observed in the length of the conidiophores. Some of the strains had lost the capacity to produce conidia. Of the 88 strains studied, $53(\approx 60 \%)$ produced pseudothecia containing fertile ascospores and a further $12(\approx 14 \%)$ produced only pseudothecial initials (Table 1$)$. There was no clear link between the capacity of production of pseudothecia or pseudothecia initials and the origin of the strains. Nevertheless, only $43 \%$ of the strains isolated before 1995 were still able to produce pseudothecia or pseudothecia initials when

TABLE 1. (continued from preceding page)

\begin{tabular}{|c|c|c|c|c|c|c|c|c|c|c|c|c|}
\hline \multirow[b]{2}{*}{ Strain $^{b}$} & \multirow[b]{2}{*}{ Location } & \multirow[b]{2}{*}{ Host } & \multirow[b]{2}{*}{ Year } & \multicolumn{2}{|c|}{ Sporulation } & \multirow[b]{2}{*}{$M A T^{\mathrm{f}}$} & \multicolumn{4}{|c|}{$\mathrm{PCR}^{\mathrm{c}}$} & \multicolumn{2}{|c|}{ Race } \\
\hline & & & & Ana. $^{d}$ & Tele. $^{\mathrm{e}}$ & & $\operatorname{ToxA}$ & $\operatorname{Tox} B$ & ToxBv & toxb & PCR & Phenotype \\
\hline 44693 & Kyrgyzstan & Bread wheat & 2003 & + & + & Ia & + & 0 & 0 & 0 & $1 / 2$ & 1 \\
\hline$\overline{44710}$ & Kyrgyzstan & Bread wheat & 2003 & \pm & + & - & + & 0 & 0 & 0 & $1 / 2$ & 1 \\
\hline$\underline{45018}$ & Kazakhstan & Bread wheat & 2003 & + & + & Ia & 0 & 0 & 0 & 0 & $\mathrm{D}$ & 1 \\
\hline$\overline{45038}$ & Nepal & Bread wheat & 2003 & + & + & Ia & + & 0 & 0 & 0 & $1 / 2$ & $1-8$ \\
\hline$\overline{45040}$ & India & Bread wheat & 2003 & + & + & - & + & 0 & 0 & 0 & $1 / 2$ & 2 \\
\hline 45041 & India & Bread wheat & 2003 & \pm & + & - & + & 0 & 0 & 0 & $1 / 2$ & $1-2$ \\
\hline$\underline{45125}$ & Russia & Bread wheat & 2003 & + & 0 & Ia & $t^{*}$ & 0 & 0 & 0 & $\mathrm{D}$ & - \\
\hline$\underline{45128}$ & Russia & Bread wheat & 2003 & + & $(+)$ & $\underline{\mathrm{IIe}}$ & 0 & 0 & 0 & 0 & $\mathrm{D}$ & - \\
\hline$\underline{45176}$ & Kazakhstan & Bread wheat & 2003 & + & + & $\overline{\mathrm{Ia}}$ & 0 & 0 & 0 & 0 & $\mathrm{D}$ & 3 \\
\hline$\overline{45179}$ & Russia & Bread wheat & 2003 & + & + & - & $+^{*}$ & 0 & 0 & 0 & $\mathrm{D}$ & 1 \\
\hline 45269 & Kazakhstan & Bread wheat & 2003 & + & + & - & $+*$ & 0 & 0 & 0 & $\mathrm{D}$ & 1 \\
\hline$\underline{45758}$ & Tajikistan & Bread wheat & 2004 & + & + & Ia & + & 0 & 0 & 0 & $1 / 2$ & 2 \\
\hline$\overline{45761}$ & Tajikistan & Durum wheat & 2004 & + & + & - & + & 0 & 0 & 0 & $1 / 2$ & 1 \\
\hline$\underline{45766}$ & Tajikistan & Bread wheat & 2004 & + & + & Ia & 0 & 0 & 0 & 0 & $\mathrm{D}$ & 3 \\
\hline$\overline{45770}$ & Tajikistan & Bread wheat & 2004 & + & + & - & + & 0 & 0 & 0 & $1 / 2$ & 1 \\
\hline$\underline{45774^{\circ} *}$ & Uzbekistan & Bread wheat & 2004 & + & + & Ia & + & 0 & 0 & 0 & $1 / 2$ & 2 \\
\hline 45776 & Uzbekistan & Bread wheat & 2004 & + & + & - & + & 0 & 0 & 0 & $1 / 2$ & 1 \\
\hline 45777 & Uzbekistan & Bread wheat & 2004 & + & + & - & + & 0 & 0 & 0 & $1 / 2$ & 1 \\
\hline$\underline{45780^{\circ} *}$ & Kazakhstan & Wheat & 2004 & \pm & $(+)$ & $\underline{\text { IIc }}$ & 0 & + & $(+)$ & + & 4 & 4 \\
\hline$\overline{45792}$ & Kazakhstan & Wheat & 2004 & + & + & $\overline{-}$ & + & 0 & 0 & 0 & $1 / 2$ & 2 \\
\hline$\underline{45953^{\circ} *}$ & Belgium & Bread wheat & 1982 & \pm & 0 & Ia & + & 0 & 0 & 0 & $1 / 2$ & $1-4$ \\
\hline 45954 & Belgium & Bread wheat & 1985 & + & + & - & + & 0 & 0 & 0 & $1 / 2$ & 1 \\
\hline$\underline{45959}$ & Kazakhstan & Wheat & 2004 & + & + & Ia & 0 & 0 & 0 & 0 & $\mathrm{D}$ & $1-3$ \\
\hline$\overline{46242}$ & Argentina & Bread wheat & 2001 & + & + & - & + & 0 & 0 & 0 & $1 / 2$ & 1 \\
\hline $46243^{\circ} *$ & Argentina & Bread wheat & 2001 & + & + & Ie & + & 0 & 0 & 0 & $1 / 2$ & 1 \\
\hline 46244 & Luxembourg & Bread wheat & 2000 & + & $(+)$ & - & + & 0 & 0 & 0 & $1 / 2$ & 1 \\
\hline$\underline{46245}$ & Luxembourg & Bread wheat & 2000 & + & $(+)$ & Ia & 0 & 0 & 0 & 0 & $\mathrm{D}$ & 3 \\
\hline$\overline{46246}$ & Nepal & Bread wheat & 2001 & \pm & $(+)$ & - & + & 0 & 0 & 0 & $1 / 2$ & 2 \\
\hline $46247^{\circ} *$ & Nepal & Bread wheat & 2001 & + & + & Ia & + & 0 & 0 & 0 & $1 / 2$ & 2 \\
\hline$\overline{46248}$ & Nepal & Bread wheat & 2001 & 0 & + & - & + & 0 & 0 & 0 & $1 / 2$ & 2 \\
\hline 46249 & Nepal & Bread wheat & 2001 & + & + & - & + & 0 & 0 & 0 & $1 / 2$ & 2 \\
\hline 46250 & Nepal & Bread wheat & 2002 & + & + & - & + & 0 & 0 & 0 & $1 / 2$ & 2 \\
\hline 46251 & Nepal & Bread wheat & 2002 & \pm & + & - & + & 0 & 0 & 0 & $1 / 2$ & 1 \\
\hline$\underline{46825}$ & Iran & Bread wheat & 2005 & \pm & $(+)$ & Ia & + & 0 & 0 & 0 & $1 / 2$ & 1 \\
\hline 46826 & Armenia & Bread wheat & 2005 & \pm & + & - & + & 0 & 0 & 0 & $1 / 2$ & 2 \\
\hline$\underline{46827}$ & Turkey & Bread wheat & 2005 & 0 & $(+)$ & Ia & + & 0 & 0 & 0 & $1 / 2$ & 1 \\
\hline$\overline{46828}$ & Turkey & Bread wheat & 2005 & 0 & $(+)$ & - & + & 0 & 0 & 0 & $1 / 2$ & 1 \\
\hline 46832 & Georgia & Bread wheat & 2005 & + & + & - & + & 0 & 0 & 0 & $1 / 2$ & 1 \\
\hline$\underline{46835}$ & Georgia & Bread wheat & 2005 & + & + & Ia & + & 0 & 0 & 0 & $1 / 2$ & $1-8$ \\
\hline$\overline{46836}$ & Georgia & Bread wheat & 2005 & + & + & - & + & 0 & 0 & 0 & $1 / 2$ & 1 \\
\hline 46842 & Azerbaijan & Wheat & 2005 & \pm & + & - & + & 0 & 0 & 0 & $1 / 2$ & 1 \\
\hline$\underline{46843^{\circ} *}$ & Azerbaijan & Triticum manati & 2005 & \pm & + & $\underline{\mathrm{Id}}$ & + & 0 & 0 & 0 & $1 / 2$ & 1 \\
\hline 46845 & Azerbaijan & T. turgilum & 2005 & + & + & - & + & 0 & 0 & 0 & $1 / 2$ & 1 \\
\hline$\underline{46860}$ & Armenia & Bread wheat & 2005 & + & + & $\mathrm{Ie}$ & + & 0 & 0 & 0 & $1 / 2$ & 2 \\
\hline 46861 & Uzbekistan & Bread wheat & 2005 & + & $(+)$ & - & + & 0 & 0 & 0 & $1 / 2$ & 1 \\
\hline 47953 & Mexico & Bread wheat & 1994 & + & + & - & + & 0 & 0 & 0 & $1 / 2$ & 1 \\
\hline 47954 & Mexico & Bread wheat & 1994 & + & + & - & + & 0 & 0 & 0 & $1 / 2$ & 1 \\
\hline 47955 & Mexico & Bread wheat & 1993 & + & + & - & + & 0 & 0 & 0 & $1 / 2$ & 1 \\
\hline 47957 & Mexico & Bread wheat & 1993 & + & + & - & + & 0 & 0 & 0 & $1 / 2$ & 1 \\
\hline 47958 & Mexico & Bread wheat & 1993 & + & $(+)$ & - & + & 0 & 0 & 0 & $1 / 2$ & 1 \\
\hline 47959 & Mexico & Bread wheat & 1993 & + & + & - & + & 0 & 0 & 0 & $1 / 2$ & 1 \\
\hline 47961 & Mexico & Bread wheat & 1993 & \pm & 0 & - & + & 0 & 0 & 0 & $1 / 2$ & $1-4$ \\
\hline
\end{tabular}


tested in 2007, suggesting a loss of capacity of teleomorph production during storage. The morphology of the teleomorph was extremely variable in terms of the abundance, thickness and length of the setae produced, as well as the length of pseudothecial necks.

Race identification. Validation of the Andrie et al. (4) multiplex PCR was initially confirmed with our reference strains for races 1 to 5 , yielding identical race profiles to those described, except for strain 90-2. This race 4 reference strain from Canada $(27,43)$ yielded a weak amplicon $(\approx 250 \mathrm{bp})$ using primer pair TB71F/TB60R, whereas the race 4 strain SD20 used by Andrie et al. (4) but not available to us did not. Nevertheless, race 4 strain MUCL 45780 from Kazakhstan behaved similarly to strain 90-2. The $P$. tritici-repentis syntype strain MUCL 18687 yielded only a weak amplicon using primer pair TA51F/TA52R for ToxA detection. For the remaining 82 strains, the genotypic race profiles were compared with the profiles obtained for the reference race strains used in this study as well as with the race phenotype data available. Loss of conidia production capacity and pathogenicity affected race phenotyping of some strains (Table 1). Of the 82 strains, 68 showed a normal amplicon with the ToxA primers. Race phenotype data were available for 59 of these strains and confirmed the concordance with race $1(\approx 61 \%)$ or race $2(\approx 29 \%)$. For $\approx 10 \%$ of the ToxA-positive strains, race phenotyping was uncertain because of intermediate or small lesion types on various differentials. The strains MUCL 45125, MUCL 45179, and MUCL 45269, originating from an area encompassing Western Siberia and Northern Kazakhstan, produced larger fragments than expected ( $>2,000 \mathrm{bp}$ ) when ToxA primers were used. MUCL 45179 and MUCL 45269 appeared as race 1 phenotype. For nine strains (MUCL 42387, MUCL 42521, MUCL 42523, MUCL 45018, MUCL 45128, MUCL 45176, MUCL 45766, MUCL 45959, and MUCL 46245), neither ToxA nor ToxB primer pairs were able to amplify the expected fragments, despite confirmation of the presence of the DNA template with MAT primers used as internal PCR control. The race phenotype of these strains appeared to be heterogeneous or uncertain, with strains MUCL 42521 showing a race 1 phenotype and MUCL 45176, MUCL 45766, and MUCL 46245 having a race 3 phenotype. Finally, MUCL 42316 isolated from Agropyron repens showed normal amplicons with the ToxB and toxb primers and weak amplicons with the ToxA and ToxB-like primers but, on Glenlea

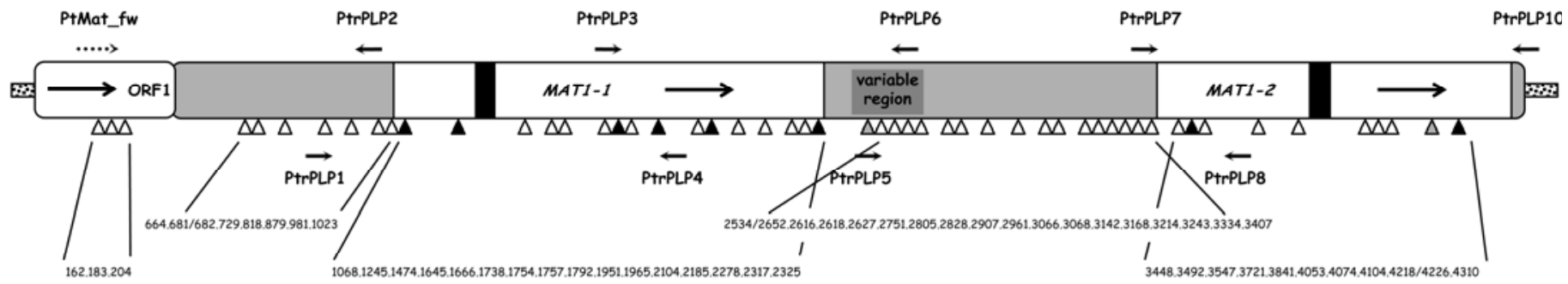

\begin{tabular}{|c|c|c|c|}
\hline Ia & $C A T$ & $C G T A C C A A$ & TAGCGCTTGTCCCT T \\
\hline Ib & CAT & $C G T A C \subset A A$ & $T A G C G C T T G T C C C T$ \\
\hline 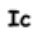 & $C A T$ & $C G T A C \subset A A$ & $T A G C G C T T G T C C C T$ \\
\hline Id & $C A T$ & $C G T A C C A A$ & $T A G C G C T T G T C T C T$ \\
\hline Le & $C A T$ & $C G T A C C A A$ & $T A G C G C T T G T C C C T$ \\
\hline If & $C A T$ & $C G T A C C A A$ & $T A G C G C T T G T C C$ \\
\hline To & CAT & $C G T A C \subset A A$ & TAGCGCTTGTCCC \\
\hline IIa & $C A T$ & $A G T A C T A A$ & $T A G C G C T T G T C C C T$ \\
\hline$T h$ & CAT & $C G T A T T A A$ & $T C G C A C G T G T C C C C$ \\
\hline IIc & TAG & $C-G C T A A$ & $G C G C G C G T A T C C C C$ \\
\hline Id & CAT & $C G T A C T A G$ & $\mathrm{~T} C G C G \mathrm{~T} G \mathrm{~T} G \mathrm{~T} \mathrm{~T} C \mathrm{~T} C$ \\
\hline TT & $C G T$ & $C G T G C T G A$ & $G \subset A T G C G C G C \subset \subset C C$ \\
\hline
\end{tabular}

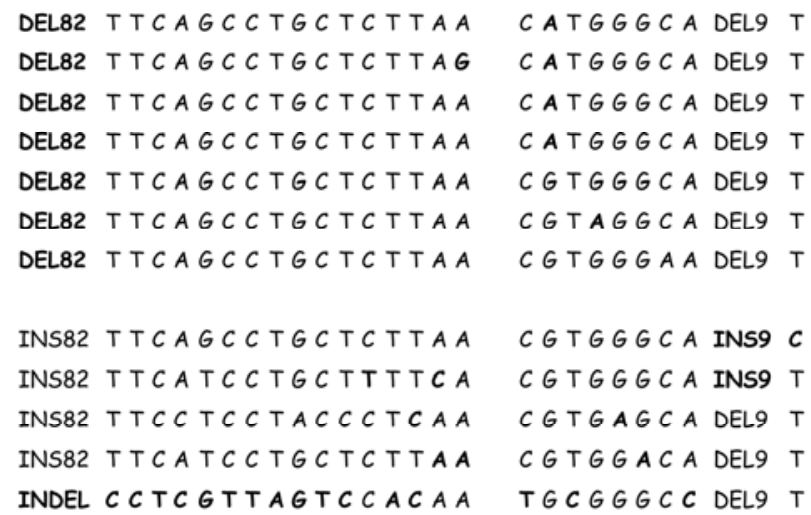

MUCL 42337 MUCL 42329 MUCL 42500 MUCL 46843 MUCL 42328 331-9 DW7

MUCL 42384 MUCL 42316 MUCL 45780 90-2 MUCL 45128

Fig. 1. Organization and distribution of polymorphism types in the Pyrenophora tritici-repentis mating type locus (MAT), drawn to proportion and showing introns (black boxes); coding regions open reading frame $(O R F) 1, M A T 1-1$, and MAT1-2 (white boxes); intergenic regions (gray boxes); and flanking DNA (thin, boxed motif). Long arrows within coding regions indicate the transcription direction for each ORF and PCR primer locations are also represented (short black arrows). All the listed primers were designed in this study apart from PtMat_fw (41). A variable region (dark gray box, shown in Figure 2) observed between the MAT1-1 and MAT1-2 ORFs is indicated. Triangles indicate the location of synonymous mutations (white), nonsynonymous mutations (black), and indels (gray). Mutations and indels are indicated in bold, as well as their exact location (in base pairs) with regard to the consensus sequence Mycothèque de l'Université catholique de Louvain 42384 (MAT haplotype IIa). Associated MAT haplotypes are indicated for each haplotype by the accession number of one representative (shown on the right).

TABLE 2. List of primers used to amplify the mating type locus region in Pyrenophora tritici-repentis strains

\begin{tabular}{|c|c|c|}
\hline Primer & Sequence $5^{\prime}-3^{\prime}$ & Origin \\
\hline PtMat_fw & CAG GAC GTT CGC CAT CGC CAT & 41 \\
\hline PtrPLP1 & CAC TGC CCA CTC ACC TTG TGC & This study \\
\hline PtrPLP2 & CAG AAC AAA GGC AGG ACT GTG AGC & This study \\
\hline PtrPLP3 & CAG ACA AGG CGC TCT CGG TTG AAG & This study \\
\hline PtrPLP4 & ATG CGC TCA GCA AGG AAG GTC G & This study \\
\hline PtrPLP5 & AAC TCG GAA CGC TGA GCC TAA TGG & This study \\
\hline PtrPLP6 & TTG ACG CCA CAG ACG GAA CAG G & This study \\
\hline PtrPLP7 & GCT TTA CTA CAA CTT TCC TCT ACC & This study \\
\hline PtrPLP8 & CTG GAA GTG CTG GAC GAG AAG ATC & This study \\
\hline PtrPLP10 & GTA CGG GCC AGC ATG ACG TGC & This study \\
\hline
\end{tabular}


and 6B365, produced small, dark-brown to black spots sometimes surrounded with tan necrotic and chlorotic zones. None of the tested strains from the CIMMYT/UCL surveys showed the genotype profile of the race 3 and race 5 reference strains.

Amplification of $\boldsymbol{M A T}$ idiomorph. The $M A T$ idiomorph was successfully amplified in 82 P. tritici-repentis strains as well as in the reference strains for races 1 to 5 and syntype strain MUCL 18687 (Table 1) via five overlapping PCRs. Four observations are worth mentioning.

First, regarding the organization of the MAT gene, the MAT1-1 gene is followed by the MAT1-2 gene, with both ORFs transcribed from left to right (Fig. 1). This gene is preceded $\left(5^{\prime}\right.$ flanking region) by a conserved ORF previously described for Phaeosphaeria nodorum (7) and Pyrenophora teres (40) and termed ORF1. As for P. teres, P. graminea, and Phaeosphaeria nodorum, the Pyrenophora tritici-repentis ORF1 sequence is conserved only in its $5^{\prime}$ region (beginning of the sequence). It is this change from the conservation to nonconservation of its sequence in the $\mathrm{C}$-terminus ( $3^{\prime}$ region) that marks the beginning of the MAT idiomorph.

Second, strains 90-2, MUCL 42316, MUCL 42384, MUCL 42386, MUCL 42387, and MUCL 45780 yielded fragments slightly larger than expected when primer pairs PtrPLP3/PtrPLP6 and PtrPLP5/PtrPLP8 were used. This corresponds to an $\approx 90$-bp insertion in these strains located between primers PtrPLP5 and PtrPLP6 in a variable region. Careful analysis of sequences in this region (Fig. 2) showed that the MAT1-1 ORF stop codon (TAA) is followed by a 13-bp sequence similar to the incomplete 3 ' termi-
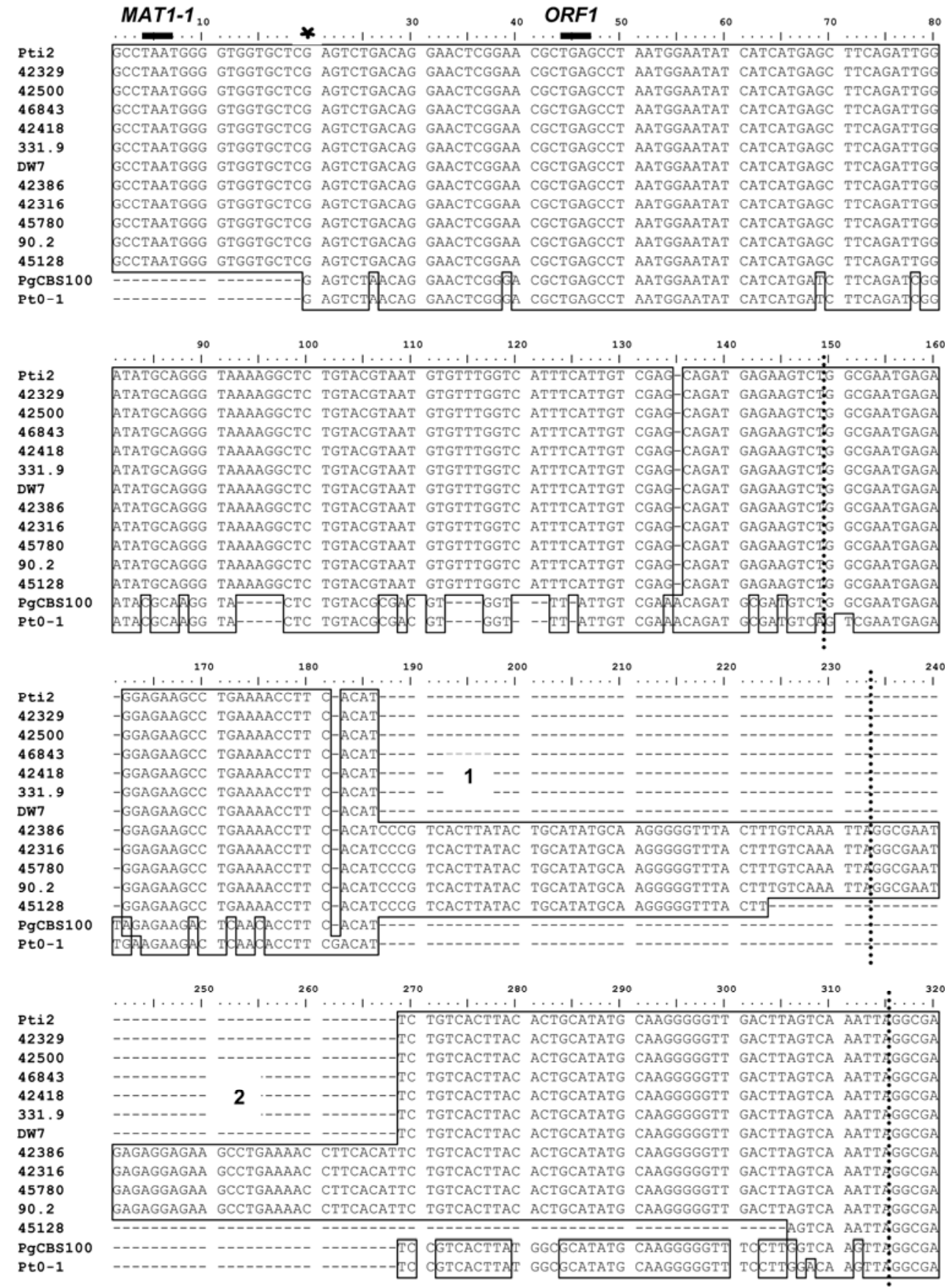

Fig. 2. Alignment of the variable region (described in Figure 1) situated between the mating type locus (MAT)1-1 and MAT1-2 open reading frames (ORFs) for the 12 distinct Pyrenophora tritici-repentis MAT haplotypes identified, as well as P. teres MAT1-2 sequence AY950586 (Pt0-1) and P. graminea MAT1-2 sequence DQ823080 (CBS 100866). Stop codons are indicated by a short horizontal line, the transition from the MAT1-1 to MAT1-2 sequence is indicated by an asterisk, and the repetitive sequences are indicated by vertical dotted lines. 
nus of the $P$. teres/P. graminea MAT1-1 idiomorph sequence (positions 7 to 19). Adjacent to this sequence is the MAT1-2 degenerate C-terminus of ORF1 (beginning at the asterisks and ending with the TGA stop codon), followed by a sequence similar to the $5^{\prime}$ MAT1-2 idiomorph sequence in $P$. teres $/ P$. graminea. It is within the latter region that repetitive sequences containing indels are observed. Similarly, a 9-bp sequence (GGGTTTCGA) situated further on in the MAT1-2 coding region (Fig. 1) is repeated three times in all strains sequenced and a fourth time only in strains MUCL 42316, MUCL 42384, MUCL 42386, and MUCL 42387.

Third, $P$. tritici-repentis strains 86-124, MUCL 42328, MUCL 42329, MUCL 46243, and MUCL 46843 produced a nonspecific profile with primer pair PtMat_fw (41) and PtrPLP2 under standard PCR conditions. The expected unique amplicon was observed for these strains when the annealing temperature was increased from 60 to $69^{\circ} \mathrm{C}$.

Finally, primer pairs targeting the MAT1-2 region (PtrPLP3/ PtrPLP6, PtrPLP5/PtrPLP8, and PtrPLP7/PtrPLP10) failed to amplify the expected fragments in syntype strain MUCL 18687.

Molecular diversity. In an exploratory genetic diversity study entailing amplification and sequencing of ITS, $g p d$, and MAT genes, 20 strains were selected on the basis of their diverse geographical and host origin as well as of their genotype and phenotype race profiles (Table 1). The results indicate that all the gpd sequences are identical to each other and to the $P$. triticirepentis reference sequence AY004838 (DAOM 107224). All but two ITS sequences are identical, with sequences for strains 86124 and 90-2 differing by a single base pair from one another and from the remaining strains. However, 51 single-nucleotide polymorphisms (of which 8 are nonsynonymous) and two indels were observed in the 12 MAT sequences haplotypes identified (Fig. 1). In a next step, the MAT gene was sequenced from an additional 20 strains. An exhaustive search resulted in three equally parsimonious trees resolving, independent of geographical origin, two major $P$. tritici-repentis sequence types (Fig. 3). The first group contains most of the strains (32 of 40) represented by seven distinct haplotypes with sequences differing, at most, by $3 \mathrm{bp}$. This group, referred to hereafter as group I, contains strains from all races apart from race 4 . The second group (group II) includes seven strains representing five distinct haplotypes. Confirmed $P$. tritici-repentis race 4 strains such as 90-2 are included in this group but other races are also represented. BLAST results indicate that the most similar MAT sequences in databases are those for $P$. teres/P. graminea, with 86 and $92 \%$ identity for MAT1-1 and MATl-2 sequences, respectively. The gpd and ITS sequences obtained for syntype strain MUCL 18687 are very distinct from the reference $P$. tritici-repentis sequences, with BLAST results inducing maximum similarity $(100 \%)$ with the D. catenaria (Drechsler) Ito strain CBS 191.29.

\section{DISCUSSION}

P. tritici-repentis is known to have a very complex interaction with its host. To date, eight distinct races that differentially express three HSTs have been described $(27,28,44,47,48)$. The existence of a fourth HST and additional races has also been suggested (4). Data from conventional phenotype race identification using a wheat differential set were confronted in this study with the results of the multiplex PCR designed by Andrie et al. (4) that enables genotypic race identification. The multiplex PCR race identification method was validated on 88 strains and, overall, supported the results obtained using the conventional method. However, discrepancies between both methods and possible new toxin gene profiles were observed, suggesting that phenotypic race identification is rather subjective. Indeed, a continuum of symptom severity and type is reduced to a conclusion on the ability or not to induce extensive necrosis or chlorosis. In addition, the size of the differential set used limits the number of possible races identified. Second, genotypic race identification still has room for improvement because new Tox genes are being discovered or suspected (44), ToxC primers await designing, and atypical profiles can be observed. Our results underline atypical ToxA profiles (amplification of a larger fragment) for strains MUCL 45125, MUCL 45179, and MUCL 45269 originating from Russia and Kazakhstan, whereas phenotype reactions clearly linked MUCL 45179 and MUCL 45269 to $P$. tritici-repentis race 1 (29,33). Interestingly, a similar host-specific toxin, ToxA, is produced by both wheat pathogens $P$. tritici-repentis (PtrToxA) and Phaeosphaeria nodorum (SnToxA), and it is thought that this gene was acquired by Pyrenophora tritici-repentis from Phaeosphaeria nodorum in a recent horizontal gene transfer (49). Mixed infections by Pyrenophora tritici-repentis and Phaeosphaeria nodorum occur frequently on wheat leaves in Western Siberia and Northern Kazakhstan (33). No further strains containing the ToxB and $T o x B v$ of the race 3 and race 5 strains were detected among the worldwide collection, suggesting a rather restricted distribution of these races. Strains MUCL 42387 (Morocco), MUCL 42521 (Belgium), MUCL 42523 (Mexico), MUCL 45018 (Kazakhstan), MUCL 45128 (Russia), MUCL 45176 (Kazakhstan), MUCL 45766 (Tajikistan), MUCL 45959 (Kazakhstan), and MUCL 46245 (Luxembourg) do not possess the genes coding for the HSTs associated with the symptoms observed on the wheat differential set, highlighting the probability of new races and HSTs. The results support previous reports of a worldwide predominance of races 1 and 2 and that phenotypic race identification should ideally be accompanied by a genotypic confirmation so as to maximize the chances of revealing the existence of new races and improving our understanding of the hostpathogen interaction $(4,11)$.

Pyrenophora tritici-repentis is clearly a homothallic loculoascomycete with a simple MAT locus organization containing both idiomorphs tandemly arranged in a single individual (Fig. 1). Upstream from the MAT locus is a region termed ORF1 coding for an unknown function. The $\mathrm{C}$-terminus region of this ORF is MAT degenerate in heterothallic species such as P. teres (40) and Phaeosphaeria nodorum (7), meaning that MAT1-1 and MAT1-2 strains each have a specific ORF1 $3^{\prime}$ end for this sequence that marks the beginning of the respective MAT idiomorph. In the case of homothallic Pyrenophora tritici-repentis, the ORF1 initiating the MAT locus encloses the MAT1-1 degenerate pattern. The MAT1-2 degenerate ORF1 pattern is situated after the MAT1-1 coding region, and lacks its conserved 5' sequence. Yun et al. (55) suggested that the self-fertile reproductive lifestyles (homothallism) of some Cochliobolus spp. have evolved from selfsterile (heterothallic) ancestors via an unequal crossing-over event between islands of identity. Similarly, Inderbitzin et al. (23) reported a lateral transfer of the MAT1-1 and MAT1-2 gene fusion across lineages in the evolution of Stemphylium spp. but the mechanism and direction of the transfer is unknown. In our study, it is likely that $P$. tritici-repentis originated from a MAT recombination of heterothallic ancestors via the islands of homology located in the 5' ORF1 sequence. However, we were unable to pinpoint the crossing-over site clearly. Similarly, the results suggest that subsequent recombination events in a handful of $P$. tritici-repentis strains might have occurred in this region where repetitive sequences are observed (Fig. 3). A repetitive 9-bp sequence within the MAT1-2 coding region could also originate from a crossing-over.

The complete sequence for the MAT locus, including the $5^{\prime}$ flanking region that contains $O R F 1$, was sequenced from $40 P$. tritici-repentis strains worldwide. Two distinct groups of strains were identified. The seven haplotypes in group I include most of the strains originating from around the world, differing at most by $3 \mathrm{bp}(\approx 0.06 \%)$ in their sequence. Group II is more heterogeneous, with five distinct haplotypes represented within the seven strains sequenced and sequences diverging $\leq 0.6 \%$ (without counting 
indels) between MUCL 45128 and MUCL 45780. The only clearcut criterion distinguishing the two groups is that race 4 strains are found only in group II; however, the results suggest that races 1 or 2 are also present in this group.

The exact status of group II strains deserves more attention. Strains such as MUCL 42316 have been isolated from alternative hosts (A. repens) and MUCL 42387 from barley, whereas strains MUCL 45128 and MUCL 45780 were isolated from small necrotic spots on wheat leaves. Does group II reflect $P$. triticirepentis's pool of diversity on grasses with overall low pathogenicity on wheat, but from where some strains with toxin profiles matching the susceptible genes in widely grown wheat genotypes (44) emerged and diversified into group I? To answer this question, it is necessary to increase the number of strains studied in this group. It should be kept in mind that the "triticirepentis" species name originated from the description in 1903 by
Diedicke (14) of a fungus collected in Germany on Triticum repens, an ancient name for $A$. repens (L.) Beauv. (31). Furthermore, it is interesting to note that ToxA was detected in some group II strains (e.g., MUCL 42384 and MUCL 42386 from wheat [Morocco] and MUCL 42316 from A. repens [Hungary]). This also raises the question of the moment and of the frequency of a putative horizontal gene transfer of ToxA from Phaeosphaeria nodorum to Pyrenophora tritici-repentis (49).

In view of a possible new distinction between the strains identified as $P$. tritici-repentis, one can already question the intraand intergroup taxonomic status. It has previously been reported that infraspecific variation is low using MAT sequences $(7,53)$. However, the importance of this gene has been validated for species-level phylogenies $(7,30,38,40,53)$ and is reported to be more pertinent than other commonly used genes. Indeed, the ITS and gpd sequence analysis carried out in this study revealed

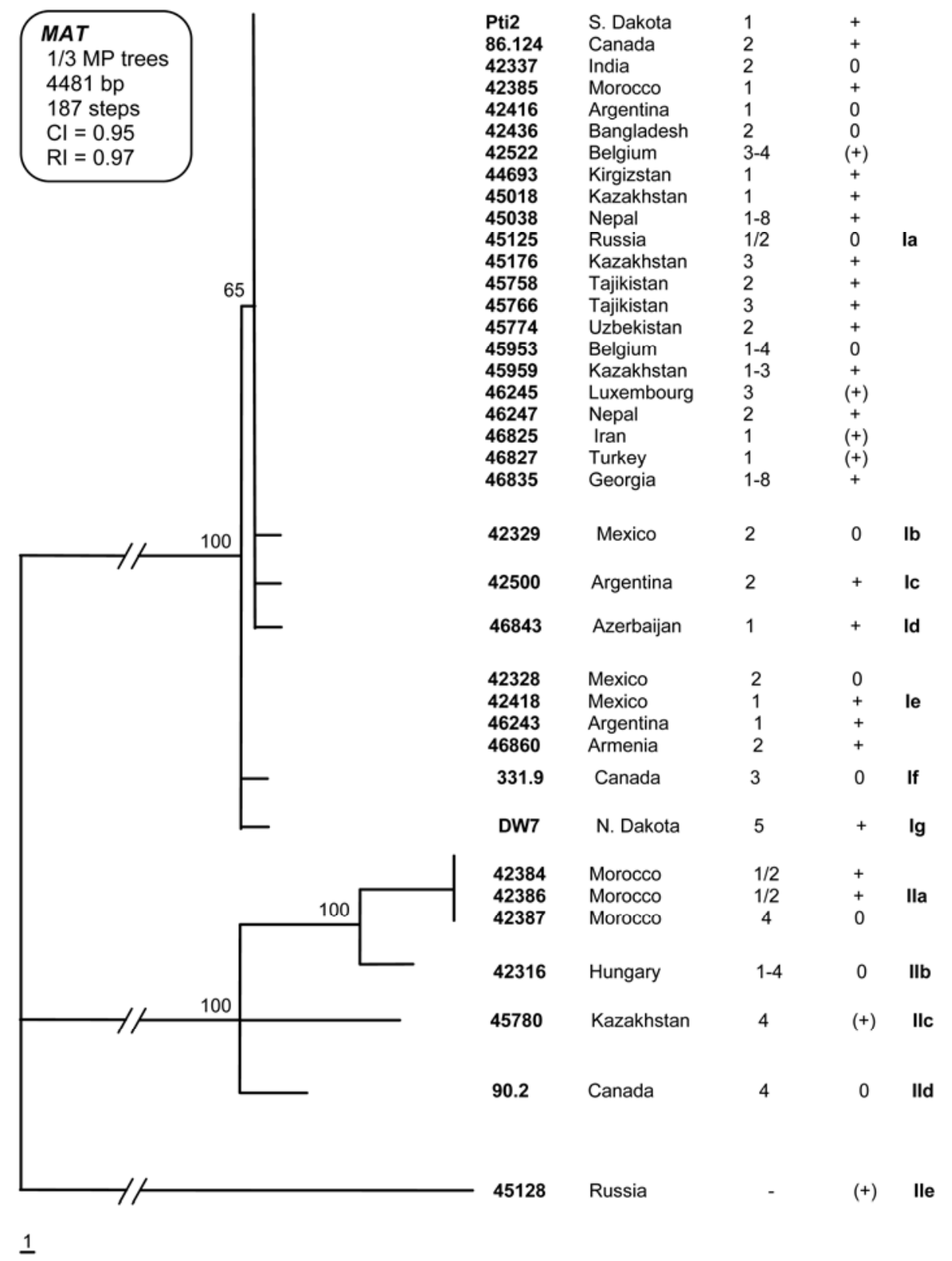

Fig. 3. One of the three most parsimonious trees generated with PAUP* v.4.0 b10 and Pyrenophora tritici-repentis strain Mycothèque de l'Université catholique de Louvain (MUCL) 45128 as an outgroup using the entire mating type locus (MAT) sequences and a portion of open reading frame (ORF)1 for $P$. tritici-repentis representatives from diverse geographical origins. Accession numbers, geographical origin, putative race, and teleomorph production, as well as associated haplotypes, are indicated next to terminal clades. Bootstrap values based on 1,000 replications are indicated in percentages at internodes when replication frequencies exceed $50 \%$. Teleomorph production was identified as $+=$ pseudothecia producing ascospores, $(+)=$ pseudothecial initials, and $0=$ no sexual structures observed. Strain MUCL 45128 was identified as basal to group II when P. teres was used as an outgroup. 
almost no diversity at all between these two groups. The ITS and gpd data suggest that another species, P. bromi, for which the $M A T$ region has not yet been sequenced, unfortunately, is one of $P$. tritici-repentis's closest relatives. For the moment, heterothallic $P$. teres and closely related $P$. graminea are $P$. tritici-repentis's closest phylogenetically related species for which the MAT gene has been completely sequenced. Two distinct formae speciales associated with distinct symptomologies (net form and spot form) have been described for $P$. teres (45). The taxonomic status of these formae speciales was recently proposed for consideration as a distinct species by Rau et al. (40), based on the divergence between the $P$. teres formae speciales MAT sequences being of similar magnitude to those between $P$. teres and $P$. graminea MAT sequences. In order to compare the $P$. teres case with the $P$. triticirepentis one, it is necessary to quantify the magnitude of the divergence of the $P$. teres/P. graminea sequences. $P$. teres (net form) differs by $5 \mathrm{bp}(M A T 1-1)$ and $4 \mathrm{bp}$ (MAT1-2) from $P$. graminea. It should be noted that the $P$. teres (spot form) is less divergent. In the case of $P$. tritici-repentis, this level of sequence diversity is easily reached between the two groups identified as well as within haplotypes belonging to group II, suggesting that there might also be several distinct taxa.

When morphological, geographical, sporulation, and teleomorph production data are combined with the MAT sequence analysis, the results suggest that there is no direct link between any of the traits. The MAT tree does not reflect the variability of the anamorph and teleomorph morphology, the capacity to produce the teleomorph, or the geographical origin of strains. In addition, for the same MAT haplotype (strains with identical sequences), teleomorph production is variable. This suggests that independent factors apart from the MAT gene intervene in the sexual cycle. Similarly, with the possible exception of race 4 , the assignation of a given race is not linked to a MAT haplotype. In addition, the previously described $P$. tritici-repentis syntype strain MUCL 18687 is clearly not $P$. tritici-repentis. The heterothallic nature of this strain (MAT1-1), coupled with the ITS and gpd sequence analysis, suggest that it could belong to $D$. catenaria (Drechsler) Ito. Subcultures of this strain in other culture collections should be checked to clarify its status and redefine a $P$. tritici-repentis syntype.

It is very important to assess the genetic variation potential of a pathogen population, considering that this plays a major role in the evolution rate of the fungus to a changing environment and its potential to overcome host and fungicide resistance $(35,50)$. It is also very important to keep track of the appearance of new haplotypes (races), which could potentially stem from lateral gene transfer or mutation and confer new, more aggressive properties on isolates. In this study, a new MAT PCR enabling the amplification of the entire $M A T$ idiomorph was developed. Primer pairs PtrPLP3/PtrPLP6 and PtrPLP5/PtrPLP8 allow a visual distinction between two distinct $P$. tritici-repentis lineages, enabling a rapid screening. Also, apart from race analysis (toxin production), MAT is the first gene that has been able to distinguish distinct lineages within $P$. tritici-repentis that could constitute distinct taxa. MAT sequence analysis also revealed that $P$. tritici-repentis could have originated from a heterothallic ancestor. However, unlike the ToxA gene, $P$. tritici-repentis MAT shows great haplotype diversity, suggesting evolution over time of the MAT gene rather than a lateral transfer from another pathogen. The fact that the same MAT haplotype occurs worldwide raises the issue of the mode of dissemination of the pathogen. Although ascospores are actively discharged from pseudothecia for only short distances, mesodistance (10 to $200 \mathrm{~km}$ ) dispersal of conidia can occur $(12,32)$. Intercontinental transfer is possible through contaminated seed (42) and straw. Additional knowledge of the emergence, race structure, and speciation of $P$. tritici-repentis is essential for a better understanding of the possible molecular co-evolution of the pathogen and its hosts (44).

\section{ACKNOWLEDGMENTS}

This work was conducted within the framework of a CIMMYT-UCL collaboration program funded by the Belgian Directorate General for Development Cooperation. We thank L. Lamari (University of Manitoba, Winnipeg, Canada) for the $P$. tritici-repentis reference strains 86-214, 331-9, and 90-2; and S. Ali and the late L. Francl (Department of Plant Pathology, NDSU), who contributed reference strains Pti2 and DW7.

\section{LITERATURE CITED}

1. Ali, S., and Francl, L. J. 2003. Population race structure of Pyrenophora tritici-repentis prevalent on wheat and noncereal grasses in the Great Plains. Plant Dis. 87:418-422.

2. Ali, S., Francl, L. J., and De Wolf, E. D. 1999. First report of Pyrenophora tritici-repentis race 5 from North America. Plant. Dis. 83:591.

3. Altschul, S. F., Madden, T. L., Schaffer, A. A., Zhang, J., Zhang, Z., Miller, W., and Lipman, D .J. 1997. Gapped BLAST and PSI-BLAST: A new generation of protein database search programs. Nucleic Acids Res. 25:3389-3402.

4. Andrie, R. M., Pandelova, I., and Ciuffetti, L. M. 2007. A combination of phenotypic and genotypic characterization strengthens Pyrenophora tritici-repentis race identification. Phytopathology 97:694-701.

5. Andrie, R. M., Schoch, C. L., Hedges, R., Spatafora, J. W., and Ciuffetti, L.M. 2008. Homologs of ToxB, a host-selective toxin gene from Pyrenophora tritici-repentis, are present in the genome of sister-species Pyrenophora bromi and other members of the Ascomycota. Fungal Genet. Biol. 45:363-377.

6. Ballance, G. M., Lamari, L., and Bernier, C. C. 1989. Purification and characterization of a host-selective necrosis toxin from Pyrenophora tritici-repentis. Physiol. Mol. Plant Pathol. 35:203-213.

7. Bennett, R. S., Yun, S.-H., Lee, T. Y., Turgeon, B. G., Arseniuk, E., Cunfer, B. M., and Bergstrom, G. C. 2003. Identity and conservation of mating type genes in geographically diverse isolates of Phaeosphaeria nodorum. Fungal Genet. Biol. 40:25-37.

8. Berbee, M. L., Pirseyedi, M., and Hubbard, S. 1999. Cochliobolus phylogenetics and the origin of known, highly virulent pathogens, inferred from ITS and glyceraldehyde-3-phosphate dehydrogenase gene sequences. Mycologia 91:964-977.

9. Bockus, W. W., and Shroyer, J. P. 1998. The impact of reduced tillage on soilborne plant pathogens. Annu. Rev. Phytopathol. 36:485-500.

10. Ciuffetti, L. M., Francl, L. J., Ballance, G. M., Bockus, W. W., Lamari, L., Meinhardt, S. W., and Rasmussen, J. B. 1998. Standardization of toxin nomenclature in the Pyrenophora tritici-repentis/wheat interaction. Can. J. Plant Pathol. 20:421-424.

11. Cuiffetti, L. M., and Tuori, R. P. 1999. Advances in the characterization of the Pyrenophora tritici-repentis-wheat interaction. Phytopathology 89:444-449.

12. De Wolf, E. D., Effertz, R. J., Ali, S., and Francl, L. 1998. Vistas on tan spot research. Can. J. Plant Pathol. 20:349-370.

13. Diaz de Ackermann, M., Hosford, R. M., Cox, D. J., and Hammond, J. J. 1988. Resistance in winter wheats to geographically differing isolates of Pyrenophora tritici-repentis and observations on pseudothecia. Plant Dis. 72:1028-1031.

14. Diedicke, H. 1903. Ueber den Zusammenhang zwischen Pleospora- und Helminthosporium- Arten. II. Bakteriol. Centralblatt Abt. II 11:52-59.

15. Di Zinno, T., Longrée, H., and Maraite, H. 1998. Diversity of Pyrenophora tritici-repentis isolates from warm wheat growing areas: Pathogenicity, toxin production, and RAPD analysis. Pages 302-312 in: Helminthosporium Blights of Wheat: Spot Blotch and Tan Spot. E. Duveiller, H. J. Dubin, J. Reeves, and A. McNab, eds. CIMMYT, El Batán, Mexico.

16. Drechsler, C. 1923. Some graminicolous species of Helminthosporium I. J. Agric. Res. 24:641-740.

17. Duveiller, E., Dubin, H. J., Reeves, J., and McNab, A., eds. 1998. Helminthosporium Blights of Wheat: Spot Blotch and Tan Spot. CIMMYT, El Batán, Mexico.

18. Effertz, R. J., Meinhardt, S. W., Anderson, J. A., Jordahl, J. G., and Francl, L. J. 2002. Identification of a chlorosis-inducing toxin from Pyrenophora tritici-repentis and the chromosomal location of an insensitivity locus in wheat. Phytopathology 92:527-533.

19. Francl, L. 1998. Components of the tan spot disease cycle. Pages 28-36 in: Helminthosporium Blights of Wheat: Spot Blotch and Tan Spot. E. Duveiller, H. J. Dubin, J. Reeves, and A. McNab, eds. CIMMYT, El Batán, Mexico.

20. Friesen, T. L., Ali, S., Klein, K., and Rasmussen, J. B. 2005. Population genetic analysis of a global collection of Pyrenophora tritici-repentis, causal agent of tan spot of wheat. Phytopathology 95:1144-1150.

21. Friesen, T. L., Ali, S., Stack, R. W., Francl, L. J., and Rasmussen, J. B. 
2003. Rapid and efficient production of the Pyrenophora tritici-repentis teleomorph. Can. J. Bot. 81:890-895.

22. Friesen, T. L., Stukenbrock, E. H., Liu, Z., Meinhardt, S., Ling, H., Faris, J. D., Rasmussen, J. B., Solomon, P. S., McDonald, B. A., and Oliver R. P. 2006. Emergence of a new disease as a result of interspecific virulence gene transfer. Nat. Genet. 38:953-956.

23. Inderbitzin, P., Harkness, J., Turgeon, B. G., and Berbee, M. L. 2005. Lateral transfer of mating system in Stemphylium. Proc. Natl. Acad. Sci. USA 102:11390-11395.

24. Kuprinsky, J. 1982. Observations on the host range of isolates of Pyrenophora trichostoma. Can. J. Plant Pathol. 4:42-46.

25. Lamari, L., and Bernier, C. C. 1989. Evaluation of wheat lines and cultivars to tan spot (Pyrenophora tritici-repentis) based on lesion type. Can. J. Plant Pathol. 11:49-56.

26. Lamari, L., and Bernier, C. C. 1989. Virulence of isolates of Pyrenophora tritici-repentis on 11 wheat cultivars and cytology of the differential host reactions. Can. J. Plant Pathol. 11:284-290.

27. Lamari, L., Sayoud, R., Boulif, M., and Bernier, C. C. 1995. Identification of a new race in Pyrenophora tritici-repentis: Implications for the current pathotype classification system. Can. J. Plant Pathol. 17:312-318.

28. Lamari, L., Strelkov, S., Yahyaoui, A., Orabi, J., and Smith, R. B. 2003. The identification of two new races of Pyrenophora tritici-repentis from the host center of diversity confirms a one-to-one relationship in tan spot of wheat. Phytopathology 93:391-396.

29. Lamari, L., Strelkov, S. E., Yahyauoi, A., Amedov, M., Saidov, M., Djunusova, M., and Koichibayev, M. 2005. Virulence of Pyrenophora tritici-repentis in the countries of the Silk Road. Can. J. Plant Pathol. 27:383-388.

30. Lepoint, P., Munaut, F., and Maraite, H. 2005. Gibberella xylarioides sensu lato from Coffea canephora: A new mating population in the $G$. fujikuroi species complex. Appl. Environ. Microbiol. 71:8466-8471.

31. Maraite, H. 1998. Evolution of the nomenclature used for Helminthosporium spp. causing leaf blight of wheat. Pages 6-9 in: Helminthosporium Blights of Wheat: Spot Blotch and Tan Spot. E. Duveiller, H. J. Dubin, J. Reeves, and A. McNab, eds. CIMMYT, El Batán, Mexico.

32. Maraite, H., Berny, J. F., and Goffin, A. 1992. Epidemiology of tan spot in Belgium. Pages 73-79 in: Advances in Tan Spot. L. J. Francl, J. M. Krupinsky, and M. P. Mc Mullen, eds. North Dakota Agriculture Experimental Station, Fargo.

33. Maraite, H., Mercado-Vergnes, D., Renard, M.-E., Zhanarbekova, A., and Duveiller, E. 2006. Relevance of pathogen diversity in management of leaf spot and leaf blight diseases on wheat in Central Asia. Agromeridian 2:105-114.

34. Martinez, J. P., Oesch, N. W., and Ciuffetti, L. M. 2004. Characterization of the multiple-copy host-selective toxin gene, ToxB, in pathogenic and nonpathogenic isolates of Pyrenophora tritici-repentis. Mol. PlantMicrobe Interact. 17:467-474.

35. McDonald B A., and Linde, C. 2002. Pathogen population genetics, evolutionary potential, and durable resistance. Annu. Rev. Phytopathol. 40:349-379.

36. Mehta, Y. R., Mehta, A., and Riede, C. R. 2004. Molecular and pathogenic variability of Pyrenophora tritici-repentis isolates causing tan spot of wheat in the state of Parana, Brazil. Summa Phytopathol. 30:436444.

37. Moreno, M. V., Stenglein, S. A., Balatti, P. A., and Perelló, A. E. 2008. Pathogenic and molecular variability among isolates of Pyrenophora tritici-repentis, causal agent of tan spot of wheat in Argentina. Eur. J. Plant Pathol. 122:239-252.

38. O'Donnell, K., Ward, T. J., Geiser, D. M., Kistler, H. C., and Aoki, T. 2004. Genealogical concordance between the mating type locus and seven other nuclear genes supports formal recognition of nine phylogenetically distinct species within the Fusarium graminearum clade. Fungal Genet. Biol. 41:600-623.

39. Pujol Vieira dos Santos, A. M., Santos Matsumura, A. T., and Van Der Sand, S. T. 2002. Intraspecific genetic diversity of Drechslera tritici- repentis as detected by random amplified polymorphic DNA analysis. Gen. Mol. Biol. 25:243-250.

40. Rau, D., Attene, G., Brown, A. H. D., Nanni, L., Maier, F. J., Balmas, V., Saba, E., Schäfer, W., and Papa, R. 2007. Phylogeny and evolution of mating-type genes from Pyrenophora teres, the causal agent of barley "net blotch" disease. Curr. Genet. 51:377-392.

41. Rau, D., Maier, F. J., Papa, R., Brown, A. H. D., Balmas, V., Saba, E., Schafer, W., and Attene, G. 2005. Isolation and characterization of the mating-type locus of the barley pathogen Pyrenophora teres and frequencies of mating-type idiomorphs within and among fungal populations collected from barley landraces. Genome 48:855-869.

42. Schilder, A. M. C., and Bergstrom, G. C. 1995. Seed transmission of Pyrenophora tritici-repentis, causal fungus of tan spot of wheat. Eur. J. Plant Pathol. 101:81-91.

43. Singh, P. K., and Hughes, G. R. 2006. Genetic similarity among isolates of Pyrenophora tritici-repentis, causal agent of tan spot of wheat. J. Phytopathol. 154:178-184.

44. Singh, P. K., Singh, R. P., Duveiller, E., Mergoum, M., Adhikari, T. B., and Elias, E. M. 2009. Genetics of wheat-Pyrenophora tritici-repentis interactions. Euphytica DOI 10.1007/s10681-009-0074-6.

45. Smedegard-Peterson, V. 1971. Pyrenophora teres f. maculata f. nov. and Pyrenophora teres f. teres on barley in Denmark. Pages 124-144 in: Yearbook of the Royal Veterinary and Agricultural University, Copenhagen.

46. Strelkov, S. E., Kowatsch, R. F., Ballance G. M., and Lamari, L. 2006. Characterization of the ToxB gene from North African and Canadian isolates of Pyrenophora tritici-repentis. Physiol. Mol. Plant Pathol. 67:164-170.

47. Strelkov, S. E., and Lamari, L. 2003. Host-parasite interaction in tan spot [Pyrenophora tritici-repentis] of wheat. Can. J. Plant. Pathol. 25:339-349.

48. Strelkov, S. E., Lamari, L., Sayoud, R., and Smith, R. B. 2002. Comparative virulence of chlorosis-inducing races of Pyrenophora tritici-repentis. Can. J. Plant Pathol. 24:29-35.

49. Stukenbrock, E. H., and McDonald, B. A. 2007. Geographical variation and positive diversifying selection in the host-specific toxin SnToxA. Mol. Plant Pathol. 8:321-332.

50. Stukenbrock, E. H., and McDonald, B. A. 2008. The origins of plant pathogens in agro-ecosystems. Annu. Rev. Phytopathol. 46:75-100.

51. Tomas, A., Feng, G. H., Reeck, G. R., Bockus, W. W., and Leach, J. E. 1990. Purification of a cultivar-specific toxin from Pyrenophora triticirepentis, causal agent of tan spot of wheat. Mol. Plant-Microbe Interact. 3:221-224.

52. Tuori, R. P., Wolpert, T. J., and Ciufetti, L. M. 1995. Purification and immunogold characterization of toxic components from cultures of Pyrenophora tritici-repentis. Mol. Plant-Microbe Interact. 8:41-48.

53. Turgeon, B. G. 1998. Application of mating type gene technology to problems in fungal biology. Annu. Rev. Phytopathol. 36:115-137.

54. White, T. J., Burns, T., Lee, S., and Taylor, J. 1990. Amplification and direct sequencing of fungal ribosomal DNA for phylogenetics. Pages 315322 in: PCR Protocols: A Guide to the Methods and Applications. M. A. Innis, D. H. Gelfand, J. J. Sninsky, and T. J. White, eds. Academic Press, San Diego, CA.

55. Yun, S.-H., Berbee, M. L., Yoder, O. C., and Turgeon, B. G. 1999. Evolution of the fungal self-fertile reproductive life style from self-sterile ancestors. Proc. Natl. Acad. Sci. USA 96:5592-5597.

56. Zhanarbekova, A. B., Mercado, D., Maraite, H., Duveiller, E., Renard M.E., Morgounov, A. I., and Koishibayev, M. 2007. Tan spot of wheat in Kazakhstan and resistance of winter wheats to four races of Pyrenophora tritici-repentis. Agromeridian 1:24-28.

57. Zhang, G., and Berbee, M. L. 2001. Pyrenophora phylogenetics inferred form ITS and glyceraldehyde-3-phosphate dehydrogenase gene sequences. Mycologia 93:1048-1063.

58. Zhang, H., Francl, L. J., Jordahl, J. G., and Meinhardt, S. W. 1997. Structural and physical properties of a necrosis-inducing toxin from Pyrenophora tritici-repentis. Phytopathology 87:154-160. 